\title{
The Journey to Realisation
}

\author{
RenaLee
}

\section{Keywords}

marine biological diversity - areas beyond national jurisdiction - policy intergovernmental conference

The theme for this year's conference is about Biodiversity Beyond National Jurisdiction (BBNJ). It is my great privilege and honour to play a role in the intergovernmental conference (IGC) to develop an international, legally binding instrument under UNCLOS for the conservation and sustainable use of marine biological diversity of areas beyond national jurisdiction. I am very grateful for the support shown to me by all delegations. Here I will address our journey to the realisation of our objective, and what some of the overarching themes are.

Recently some of you may have come across news reports of the latest report issued by the Intergovernmental Science-Policy Platform on Biodiversity and Ecosystem Services (IPBES). It is, I believe, the biodiversity equivalent of the Intergovernmental Panel on Climate Change or IPCC. The report, which is known as the IPBEs Global Assessment Report on Biodiversity and Ecosystem Services, is the first of its kind and is a comprehensive assessment of the state of the earth's biodiversity. Although I have only read the news reports, they make for sober reading. Out of eight million species of animals and plants on earth, it is estimated that up to one million species are threatened with extinction over the next few decades. It means that in our lifetime, we could possibly see over one million species of plants and animals disappear forever. This is a rate of extinction which is higher than the average for the last 10 million years. These figures are mind boggling. And this is, I assume, for known species of plants and animals. There is so much that we do not know about the areas beyond national jurisdiction, in the deep ocean and seabed.

To assist policy makers, the Report identifies the direct drivers of change. Top of the list, meaning the biggest driver, is land and sea use changes, followed by direct exploitation of organisms. These direct drivers are the result of an array of different reasons but this is not the place to discuss these reasons. 
The Report however, is not all gloom and doom. There is hope. These are projected outcomes and there is still time for us to make a difference. To quote the Chair of the IPBES, Sir Robert Watson, "Through 'transformative change', nature can still be conserved, restored and used sustainably". But if we want to make that difference and develop more sustainable pathways, we must act urgently.

What is the relevance of the Report to our work in the IGC? The Report covers not just terrestrial biodiversity but marine biodiversity as well. The one million species threatened with extinction include almost $33 \%$ of reef-forming corals and more than one third of marine mammals. So this Report underscores what we all know - that the work of the IGC is urgent. That is part of our mandate by the way; resolution $72 / 249$ refers to developing the instrument "as soon as possible". Indeed, at the end of the last session of the IGC in early April, some member states noted that there remained two more of the four sessions mandated in $72 / 249$. This is not to say that the new instrument is going to be the "silver bullet" that solves all the ills plaguing the areas beyond national jurisdiction; it is not - we are governed by our mandate. But it can be part of the transformative change that the IPBES is calling for. And in fact some of the "levers" of change described in the Report are what we are working on: capacity-building, integrated and cross-sectoral cooperation, precautionary actions, and the rule of law.

So the question is, how do we fulfil the mandate that has been given to us? In other words, what is the pathway to realisation of our objective? I take process first: over the course of the IG C, I have had reason to give a lot of thought to process issues because process matters. What I have come to realise is that there is no one single pathway, no one single process to realisation. There are many possible pathways to realisation. I personally think it is important that the process is one that is systematic, that allows participants to follow the work and to be heard. Yes, I am keenly aware of the urgency of our work and I value the advice of those who want to pick up the pace but as I have said before: sometimes, we have to go slow to go fast. Opportunities like this IGC are not around every corner so it is important that we do not squander the opportunity that is before us; it is important to take the time to get things right. But precisely because there are many possible pathways, I hope that those of you who participate in the IGC will continue to share your ideas with me and with your bureau members. At the same time, I want to express my gratitude for the flexibility that delegations have shown thus far with regard to the process, and I hope that this can be continued, as we may need to adjust our process as the situation demands it. 
But while process matters, it is inconsequential without the substance. The substance is what drives our process. Once the dust has settled, the substance is what remains. And the substance is what will bring about real results, what will make a difference. At the start of the IG C, I said that my vision was to build a fair, balanced and effective instrument.

To me, a fair outcome is one where the various interests and concerns are taken into account. This is not to say that we will all get what we want. Nonetheless, in our quest for consensus, we must seek to give consideration to different viewpoints, not dismiss them out of turn, and consider how they can be accommodated if possible. A balanced outcome speaks to the package that we are seeking to build. Many delegations have, in the past, referred to the "delicate balance" of rights and duties, of different interests, that are reflected in UNCLOS. In building our BBNJ package, I hope we can strive to achieve a balance as well, both within each of the elements and across the elements of the package.

An effective outcome is something I have been and continue to focus on. There are a number of aspects to effective outcomes but the two main pillars, in the context of the вв NJ instrument, are universality and implementability. Because we are talking about areas beyond national jurisdiction, it is important that we bring on board as many people as possible, which means seeking to achieve a high rate of ratification of the new instrument. It is equally important that the outcome is an implementable one. This means is that it should be clear how the provisions of the в BNJ instrument are to be implemented. The twin pillars of an effective outcome are important because the implementation of what we decide to do by as many people as possible is what will bear fruit, what will produce real results, in the areas beyond national jurisdiction.

The search for an implementable outcome is why I have, in the IGC process, placed an emphasis on processes and people - how will we do what we say we want to do and who's going to do it. For example, it is not enough to say we want to apply an area-based management tool. There should be an understanding of how are we going to do so; in other words, what the process is, and who the actors are. The areas beyond national jurisdiction are not empty. There are many players out there, and it would be helpful to know who will be doing what, and to work out the place of this BBNJ instrument in the universe of ocean governance. This will help us to avoid what I call the "everybody, somebody, nobody" syndrome, where everybody knows somebody has to do it, but nobody does it because everybody thinks somebody else is doing it. Or just as problematic: everybody knows somebody has to do it, but everybody does it because nobody thinks somebody else is doing it. 
One significant hallmark of the IGC is the high level of engagement displayed by all delegations, and that includes the observer delegations - that was very evident at the last session. And I can see that in many respects, delegations are trying to move beyond the "headlines" as it were, to delve into issues with greater specificity. Delegations are trying to tease out the elements of the benefit-sharing regime for marine genetic resources, to work out the process for the application of area-based management tools, to establish what's involved in an environmental impact assessment, and to consider how capacity and technology needs can be met, while harnessing on-going efforts. But there is still much ground to cover because these are complex issues. For example, we need a better handle on what is the role of intellectual property rights in the context of marine genetic resources, how area-based management tools will be implemented, who will undertake strategic environment assessments, and how to sustain capacity building and technology transfer efforts, and there are more of these issues to tackle.

This is why conferences such as this are important. Yesterday, at the reception, Madam President of the WMU quoted Nelson Mandela who said that "[e]ducation is the most powerful weapon which you can use to change the world". Conferences such as this one are important in educating people on the issues that we are tackling in the IGC. I see that the sub-theme of this year's conference is "Intractable challenges and potential solutions". I am pleased to note that even intractable issues have solutions. The ideas that you seed here may bear fruit in the IGC. The high level of engagement and dedication shown by delegations give me the confidence to tell you that given time, if we persist, we will fulfil our mandate. 